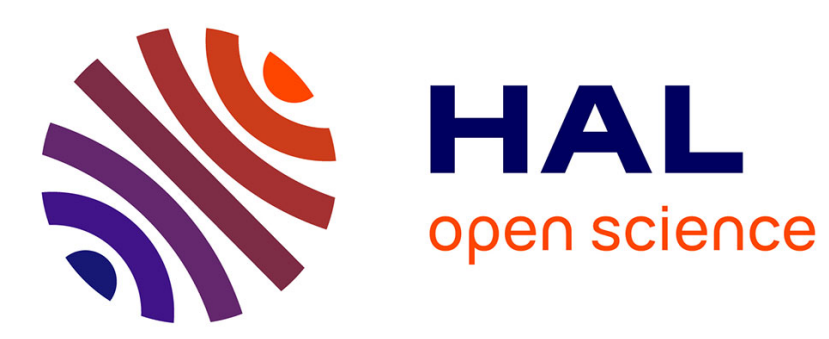

\title{
Dispersive Liquid-Liquid Microextraction for the Quantitation of Terpenes in Wine
}

G. Bergler, V. Nolleau, C. Picou, M. Perez, A. Ortiz-Julien, M. Brulfert, C. Camarasa, A. Bloem

\section{- To cite this version:}

G. Bergler, V. Nolleau, C. Picou, M. Perez, A. Ortiz-Julien, et al.. Dispersive Liquid-Liquid Microextraction for the Quantitation of Terpenes in Wine. Journal of Agricultural and Food Chemistry, 2020, 68 (47), pp.13302-13309. 10.1021/acs.jafc.9b08222 . hal-02927841

\section{HAL Id: hal-02927841 \\ https://hal.inrae.fr/hal-02927841}

Submitted on 19 Feb 2021

HAL is a multi-disciplinary open access archive for the deposit and dissemination of scientific research documents, whether they are published or not. The documents may come from teaching and research institutions in France or abroad, or from public or private research centers.
L'archive ouverte pluridisciplinaire HAL, est destinée au dépôt et à la diffusion de documents scientifiques de niveau recherche, publiés ou non, émanant des établissements d'enseignement et de recherche français ou étrangers, des laboratoires publics ou privés. 


\title{
Dispersive Liquid-Liquid Microextraction for the Quantitation of Terpenes in Wine
}

\author{
G. Bergler,* V. Nolleau, C. Picou, M. Perez, A. Ortiz-Julien, M. Brulfert, C. Camarasa, and A. Bloem
}

\begin{abstract}
To study the contribution of yeasts to the formation of terpene derivatives during winemaking, a dispersive liquidliquid microextraction gas chromatography mass spectrometry method was developed for the quantitation of terpenes in white wines, synthetic wine, and a fermented synthetic medium. A mixture of acetone (disperser solvent) and dichloromethane (extraction solvent) was added to $5 \mathrm{~mL}$ of sample. The proposed method showed no matrix effect, good linearity in the enological range (from 10 to $200 \mu \mathrm{g} / \mathrm{L}$ ), good recovery, and satisfactory inter- and intraday reproducibilities (below 20 and $15 \%$ of the relative standard deviation). This sample preparation technique is very interesting for high-throughput studies and economic and environmental reasons because it is fast and easy to operate with high enrichment and consumes a low volume of organic solvents. This method was applied to explore the capacities of 40 yeast strains to produce terpene compounds during fermentation of Chardonnay and Ugni Blanc musts as well as in a synthetic medium. Interestingly, most of the studied compounds were detected and quantified in the resulting wines. This study shows that yeast strains can intrinsically produce terpene derivatives under enological conditions and also highlights the differences between the de novo biosynthesis of terpenes and their precursor-linked production.
\end{abstract}

KEYWORDS: wine yeast diversity, terpene production, DLLME-GC-MS

\section{INTRODUCTION}

In a highly competitive worldwide market, a current challenge for the beverage sector is to diversify the range of products and to offer wines and spirits with typicity and character. The aroma of a wine is comprised of several thousand molecules, which are classified into varietal aromas, present in berries and typical of grape variety, and fermentation aromas, originating from yeast metabolism, and post-fermentative aromas, produced by chemical reactions during aging. The metabolic pathways involved in the formation of the most abundant fermentative volatile compounds, including acetate esters, ethyl fatty acid esters, higher alcohols, and volatile fatty acids, are now well-identified. ${ }^{1,2}$ Therefore, other compounds, including terpenoids, although produced by yeast in smaller quantities, have a great sensory impact on the quality of wines. To date, little is known about the biosynthesis pathways involved in their formation as well as on the ability of yeasts from the wine microbial consortium to produce these molecules.

Isoprenoids play a key role in microbial physiology and are involved in cell wall biosynthesis, membrane function, and electron transport. ${ }^{3,4}$ In the winemaking sector, these molecules are of interest as a result of their floral fragances. ${ }^{5}$ In wines, the major terpenoids are monoterpenols, linalool, nerol, $\alpha$-terpineol, geraniol, and citronellol, ${ }^{6}$ which can be chemically interchanged or biologically interconverted, ${ }^{7}$ depending upon the yeast species used for fermentation. ${ }^{8}$ These compounds first originated from cultivars that naturally contain high amounts of free terpenes, such as Muscat or Gewürztraminer cultivars (up to $1.5 \mathrm{mg} / \mathrm{L}$ of free terpenes). ${ }^{9,10}$ Terpenes may also be present in must as glycosylated precursors, for which terpene is combined with $\beta$-D- glucopyranose, itself bound to another carbohydrate (usually rhamnopyranose or arabinofuranose). ${ }^{6,11,12}$ The free terpene/ bound terpene ratio and their individual concentrations can greatly differ depending upon the grape variety. ${ }^{9}$ The release of terpenes is a two-step process, first involving cleavage between the terminal sugar and rhamnose or arabinose by $\alpha$-Lrhamnosidase or $\alpha$-L-arabinosidase and the further hydrolysis of the intermediate by $\beta$-D-glucosidase. ${ }^{13,14}$ Some yeast species, such as Saccharomyces cerevisiae and Hanseniaspora sp., are able to produce $\beta$-D-glucosidases. ${ }^{15,16}$ Finally, terpene derivatives found in wines can be derived from the metabolism of yeast, as the ability of $S$. cerevisiae to produce monoterpenes has been reported. ${ }^{5}$ Overall, three potential routes have been described for the formation of isoprenoids, including the involvement of the mevalonate pathway (MVA) reported in eukaryotes and bacteria, $^{17}$ the 2-C-methyl-D-erythritol 4-phosphate (MEP) pathway described in plants and bacteria, and the methyl crotonyl CoA (MCC) pathway identified in S. cerevisiae mitochondria and related to leucine catabolism. ${ }^{5}$ However, the effective contribution of these metabolic pathways to terpenol formation during wine fermentation remains poorly elucidated. In addition, these molecules are produced at low levels $(4 \mu \mathrm{g})$ $\mathrm{L}$ linalool and $3 \mu \mathrm{g} / \mathrm{L}$ geraniol), underlining the importance of 
having a dedicated accurate analytical method for the quantitation of these molecules during fermentation.

During analytical procedures, sample pretreatments, such as liquid-liquid or solid-phase extraction (LLE or SPE, respectively), allow for the extraction of the targeted analytes from complex matrices as well as pre-concentration of the compounds, which makes them easier to detect and quantitate. These commonly used sample pretreatments require extensive development work and are time-consuming. ${ }^{18}$ Furthermore, for trace analysis using LLE, the use of large volumes of solvents has negative economic, environmental, and health impacts. Concerning SPE, the major issue relies on the use of single use of cartridges, generating large amounts of waste.

To address these drawbacks, microextraction techniques have emerged as alternative methodologies. In this context, solid-phase microextraction (SPME) is a solvent-free process enabling the extraction and pre-concentration of analytes. ${ }^{19,20}$ Nonetheless, it is an expensive method that uses a fragile fiber with a limited lifetime. ${ }^{21}$ This approach has been improved by the development of dispersive liquid-liquid microextraction (DLLME) based on the addition of a disperser solvent to the organic phase to reduce the interfacial tension between the aqueous phase and the extraction solvent. ${ }^{22,23}$ The feasibility of the method depends upon the choice of solvents, which first have to be chemically compatible with the compounds to be measured. Therefore, the dispersing solvent has to be soluble in aqueous solutions and miscible with the extraction solvent. ${ }^{24}$ The extraction solvent is required to be insoluble in water and to have a different density than water for the phase separation.

DLLME has already been applied to quantitate a wide cluster of trace compounds as a result of the concentration factor of the technique. As an example, it has been used to detect and quantitate pesticides in water samples, with limits of detection (LODs) between 3 and $10 \mathrm{pg} / \mathrm{mL} .^{22,25,26}$ Interestingly, this extraction technique was previously used in a wine matrix to analyze volatile phenols in a linear range between 50 and $1500 \mu \mathrm{g} / \mathrm{L}$ 4-ethylguaiacol and 4-ethylphenol. ${ }^{27}$

The main aim of this study was to provide a comprehensive view of the potential of wine yeasts to contribute to the perception of terpenols in wines and to discriminate de novo production from precursor-related production. To do this, because terpene derivatives are present in low concentrations in wines, an analytical method relying on DLLME coupled to gas chromatography-mass spectrometry (GC-MS) was implemented for accurate detection and quantitation of these molecules at the end of fermentation, and its use was validated under enological conditions.

\section{MATERIALS AND METHODS}

Chemicals and Standards. Linalool (CAS Registry Number 7870-6), geraniol (CAS Registry Number 106-24-1), citronellol (CAS Registry Number 106-22-9), $\alpha$-terpineol (CAS Registry Number 98555-5), nerol (CAS Registry Number 106-25-2), geranyl acetate (CAS Registry Number 105-87-3), and nootkatone (CAS Registry Number 4674-50-4) were purchased from Sigma-Aldrich (Saint-QuentinFallavier, France). 4-Nonanol (CAS Registry Number 143-08-8, Sigma-Aldrich) and benzaldehyde- $d_{6}$ purchased from CDN Isotopes (Quebec, Canada) were used as internal standards. All solvents were of high-performance liquid chromatography (HPLC) grade. Absolute ethanol (CAS Registry Number $64-17-5$, purity of $\geq 99.9 \%$ ) was obtained from Carlo Erba (Val de Reuil, France). Acetone (CAS Registry Number 67-64-1, purity of $\geq 99.5 \%$ ) and dichloromethane (CAS Registry Number $75-09-2$, purity of $\geq 99.9 \%$ ) were purchased from Honeywell (Seelze, Germany).
Analytical Standard Solution. A mixed standard stock solution including all of the terpene derivatives was prepared in $100 \%$ absolute ethanol at a concentration of $10 \mathrm{~g} / \mathrm{L}$. The solution was stored in dark glass tubes at $-20{ }^{\circ} \mathrm{C}$. The stability of the solution was checked regularly by GC-MS. An internal standard solution of benzaldehyde$d_{6}$ was prepared at $30 \mathrm{mg} / \mathrm{L}$ in absolute ethanol.

Sample Preparation. A total of $5 \mathrm{~mL}$ of samples supplemented with $20 \mu \mathrm{L}$ of internal standard was extracted using DLLME with 870 $\mu \mathrm{L}$ of acetone (the disperser solvent) and $500 \mu \mathrm{L}$ of dichloromethane (extracting solvent). The mixture was shaken by vortexing for $20 \mathrm{~s}$. The samples were centrifuged at $2000 \mathrm{rpm}$ for $20 \mathrm{~min}$ at $4{ }^{\circ} \mathrm{C}$. The organic phase was transferred to a $2 \mathrm{~mL}$ vial before analysis.

GC-MS. Analysis was performed using a GC Trace Ultra gas chromatograph (Thermo Fisher, Waltham, MA, U.S.A.) equipped with a CTC Combi PAL (Shimadzu, Colombia, MD, U.S.A.) and coupled to a TSQ8000 Series mass spectrometer (Thermo Fisher, Waltham, MA, U.S.A.). A volume of $1 \mu \mathrm{L}$ was injected into GC-MS (injector set at $240{ }^{\circ} \mathrm{C}$ ) in splitless mode.

The gas chromatograph was equipped with a DB-FFAP column $(30 \mathrm{~m} \times 0.25 \mathrm{~mm} \times 0.25 \mu \mathrm{m}$ film thickness, Agilent Technologies, Santa Clara, CA, U.S.A.). The gas carrier was helium (BIP quality, Air Liquide) at a flow rate of $1.2 \mathrm{~mL} / \mathrm{min}$. The column oven temperature program used was as follows: initial temperature of $40^{\circ} \mathrm{C}$ for $1 \mathrm{~min}$, then increased to $210{ }^{\circ} \mathrm{C}$ at a rate of $4{ }^{\circ} \mathrm{C} / \mathrm{min}$, and finally increased to $240{ }^{\circ} \mathrm{C}$ at $20{ }^{\circ} \mathrm{C} / \mathrm{min}$ for $10 \mathrm{~min}$. For quantitation, mass spectra were recorded in selected ion monitoring (SIM) mode with positive ion electronic ionization of $70 \mathrm{eV}$. The transfer line temperature was set at $240{ }^{\circ} \mathrm{C}$.

The identification of terpenes in wine was performed by comparing retention times and mass spectra to the pure analytical standard injected using GC-MS and the National Institute of Standards and Technology (NIST) mass spectra database. A mass spectral database regrouping each compound was created to develop a GC-MS/SIM acquisition method. The retention times, retention indexes, and qualifying and quantifying ions are summarized in Table $S 1$ of the Supporting Information. ${ }^{34}$

Validation Procedure of the Method. For each validation step, the homoscedasticity of each data series was verified using a Fisher test.

To determine the presence of a matrix effect, 5 replicates of one concentration $(50 \mu \mathrm{g} / \mathrm{L})$ were extracted and injected. The wine model (water, $12 \%$ ethanol, and $5 \mathrm{~g} / \mathrm{L}$ tartaric acid at $\mathrm{pH} 3.5$ ) was used as the standard matrix for the calculations in this study. For each compound, the reduced standard deviation $\left(\mathrm{SD}_{\mathrm{red}}\right)$ of the reduced areas was calculated and compared to the wine model. Statistically, if the $\mathrm{SD}_{\text {red }}$ values are below 2, there is no matrix effect.

For linearity, calibration curves were constructed in model wine, white wine (Sauvignon), and fermented synthetic must (SM). Linearity was studied between 10 and $200 \mu \mathrm{g} / \mathrm{L}$. Statistically, a lack-of-fit test was used to determine the linearity of the data series by performing three independent calibrations.

For recovery, $50 \mu \mathrm{g} / \mathrm{L}$ of each analyte (geraniol, nerol, linalool, citronellol, $\alpha$-terpineol, geranyl acetate, and nootkatone) was added to the studied matrix and the concentrations were calculated using the calibration equation. The recovery was calculated using the formula

$$
\text { recovery }(\%)=\frac{C_{\text {calibration }}}{C_{\text {actual }}} \times 100
$$

where $C_{\text {actual }}$ is the real concentration added to the matrix $(50 \mu \mathrm{g} / \mathrm{L})$ and $C_{\text {calibration }}$ is the calculated concentration using the calibration equation.

The limit of quantitation (LOQ) and LOD were evaluated using two concentrations ( 25 and $50 \mu \mathrm{g} / \mathrm{L}$ ). Then, the signal-to-noise ratio $(\mathrm{S} / \mathrm{N})$ was calculated. The next step was the calculation of the mean $\mathrm{S} / \mathrm{N}\left(\mathrm{S} / \mathrm{N}_{\text {mean }}\right)$ and the mean of the concentrations $\left(C_{\text {mean }}=39.5 \mu \mathrm{g} /\right.$ $\mathrm{L}$ in this experiment).

$$
\mathrm{LOD}=\frac{3 \mathrm{C}_{\text {mean }}}{\mathrm{S} / \mathrm{N}_{\text {mean }}}
$$




$$
\mathrm{LOQ}=\frac{10 C_{\text {mean }}}{\mathrm{S} / \mathrm{N}_{\text {mean }}}
$$

To determine intraday variability, 10 replicates of one concentration level $(50 \mu \mathrm{g} / \mathrm{L})$ were independently extracted and injected on the same day. The reduced areas were determined (area of the analytes divided by the area of the internal standard), and the intraday variability was determined by calculating the relative standard deviation (RSD) and performing Fisher tests to show the significance of the results. To determine interday variability, 5 replicates of two concentration levels were independently prepared and extracted every day for 3 days.

The RSD should not exceed $15 \%$ for intraday variability and $20 \%$ for interday variability.

Yeast Strains and Precultures. A total of 41 yeast strains were used: 29 S. cerevisiae strains (referred to as L1-L26, all produced and provided by Lallemand SA, Montreal, Canada) and 12 nonSaccharomyces strains: Torulaspora delbrueckii strains (TD86 and TD99), Lachancea thermotolerans strains (LT65 and LT75), Starmerella bacillaris strains (SB1 and SB2), Hanseniaspora osmophila strain (HO), Zygotorulaspora florentina strain (ZF), and strains provided by Lallemand SA (referred to as L27, L28, and L29). Strains are stored at $-80{ }^{\circ} \mathrm{C}$ in a mix of YEPD medium $(10 \mathrm{~g} / \mathrm{L}$ yeast extract, $20 \mathrm{~g} / \mathrm{L}$ peptone, and $20 \mathrm{~g} / \mathrm{L}$ dextrose) and glycerol (15\%). For precultures, one colony of each strain was used to inoculate a sterile $50 \mathrm{~mL}$ tube containing $25 \mathrm{~mL}$ of YEPD medium. The strains were grown for $24 \mathrm{~h}$ at $28^{\circ} \mathrm{C}(190 \mathrm{rpm})$. Then, the tubes were centrifuged ( $5 \mathrm{~min}, 4500 \mathrm{rpm}$, and $4{ }^{\circ} \mathrm{C}$ ), and the pellet was resuspended in 15 $\mathrm{mL}$ of water containing $9 \mathrm{~g} / \mathrm{L} \mathrm{NaCl}$. The inoculation rate for each strain was $1 \times 10^{6}$ colony-forming units $(\mathrm{CFU}) / \mathrm{mL}$.

Fermentation Media and Fermentation Conditions. Natural musts (Chardonnay 2016 and Ugni Blanc 2016) and a SM were used in this study. The composition of the natural musts [sugars, acids, yeast assimilable nitrogen (YAN), and $\mathrm{pH}$ ] is shown in Table $\mathrm{S} 2$ of the Supporting Information. The composition of the SM was based on the Chardonnay must concerning the sugar content, $\mathrm{pH}$, and YAN (ammonium chloride and amino acids). Concerning the other nutrients, the SM was prepared as described by Rollero et al. ${ }^{28}$

The nitrogen source of the SM was composed of ammonium chloride and amino acids. The stock solution of amino acids was composed of proline $(54.4 \mathrm{~g} / \mathrm{L})$, alanine $(12.8 \mathrm{~g} / \mathrm{L})$, arginine $(15.4 \mathrm{~g} /$ $\mathrm{L})$, aspartic acid $(3.4 \mathrm{~g} / \mathrm{L}), \gamma$-aminobutyric acid $(7.7 \mathrm{~g} / \mathrm{L})$, glutamine $(7.0 \mathrm{~g} / \mathrm{L})$, glutamic acid $(8.3 \mathrm{~g} / \mathrm{L})$, glycine $(0.44 \mathrm{~g} / \mathrm{L})$, histidine $(2.0$ $\mathrm{g} / \mathrm{L})$, isoleucine $(0.94 \mathrm{~g} / \mathrm{L})$, leucine $(1.4 \mathrm{~g} / \mathrm{L})$, lysine $(0.3 \mathrm{~g} / \mathrm{L})$, methionine $(0.3 \mathrm{~g} / \mathrm{L})$, phenylalanine $(1.8 \mathrm{~g} / \mathrm{L})$, serine $(7.6 \mathrm{~g} / \mathrm{L})$, threonine $(5.6 \mathrm{~g} / \mathrm{L})$, tryptophan $(1.3 \mathrm{~g} / \mathrm{L})$, tyrosine $(1.3 \mathrm{~g} / \mathrm{L})$, and valine $(3.2 \mathrm{~g} / \mathrm{L})$. To reach $192 \mathrm{mg} / \mathrm{L}$ YAN, $11.7 \mathrm{~mL}$ of amino acid solution and $200 \mathrm{mg} / \mathrm{L} \mathrm{NH}_{4} \mathrm{Cl}$ were added. A concentration of $4 \mathrm{mg} /$ $\mathrm{L} \beta$-sitosterol was added to the Chardonnay must and SM to satisfy the yeast requirements during anaerobic growth. The stock solution was composed of $20 \mathrm{~g} / \mathrm{L}$ phytosterols in a mix of Tween 80 and absolute ethanol $(1: 1, \mathrm{v} / \mathrm{v})$.

Fermentations were carried out in $300 \mathrm{~mL}$ bioreactors containing $270 \mathrm{~mL}$ of must equipped with fermentation locks to maintain anaerobiosis at $24{ }^{\circ} \mathrm{C}$. Fermentation was monitored by a fermentation robot (PhenOFerm) that determines $\mathrm{CO}_{2}$ release by measuring the weight of each bioreactor every hour.

\section{RESULTS AND DISCUSSION}

Validation of the Method. To study the volatile production of wine yeasts, high-throughput fermentations were carried out. These studies require the fast extraction of volatile compounds at low concentrations (between 10 and $200 \mu \mathrm{g} / \mathrm{L}$ ). The studied method for the quantitation of terpenes in wines relies on the use of DLLME. Usually, very low volumes of extracting solvents are used for DLLME, between 10 and $500 \mu \mathrm{L}$ depending upon the sample volume. ${ }^{29,30}$ In our research group, previous studies have resulted in the use of $870 \mu \mathrm{L}$ of acetone as the disperser solvent. This volume lies between the values found in the literature to obtain a proper dispersion (between $500 \mu \mathrm{L}$ and 2 $\mathrm{mL}$ for $5 \mathrm{~mL}$ of aqueous sample). In addition, $500 \mu \mathrm{L}$ of dichloromethane was used as the extraction solvent. This value represents a good compromise between the theoretical 10 -fold enrichment factor and the problems of handling the extract. This enrichment factor was convenient for the recoveries of the target compounds in wine.

In addition, the analytical method has to enable us to compare low concentrations of the targeted compounds (linalool, $\beta$-citral, $\alpha$-terpineol, $\alpha$-citral, geranyl acetate, citronellol, nerol, geraniol, and nootkatone) in a complex matrix. Therefore, the dedicated method was validated for nine terpenoids that can be found in wines in this concentration range (between 10 and $200 \mu \mathrm{g} / \mathrm{L}$ ). The results of the method validation are summarized in Tables 1 and 2 .

Table 1. Determination of Matrix Effects between the Model Wine, White Wine, and Fermented SM for the Quantitation of Terpenes

\begin{tabular}{lcc} 
& \multicolumn{2}{c}{$\mathrm{SD}_{\text {red }}{ }^{a}$} \\
\cline { 2 - 3 } compound & model wine versus SM & model wine versus white wine \\
linalool & 1.42 & 1.94 \\
$\beta$-citral & 1.48 & 1.54 \\
$\alpha$-terpineol & 1.53 & 1.99 \\
$\alpha$-citral & 1.10 & 1.06 \\
geranyl acetate & 1.55 & 1.18 \\
citronellol & 1.97 & 1.62 \\
nerol & 1.26 & 1.83 \\
geraniol & 0.82 & 0.85 \\
nootkatone & 0.74 & 1.34
\end{tabular}

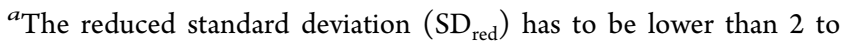
confirm that there is no matrix effect.

One problem in quantitative analysis is matrix effects, in which the compounds of the matrix co-extracted with the target compounds can affect the signal response, resulting in poor analytical performance. In this study, we assessed the matrix effects of three different matrices: model wine, white wine, and fermented SM to evaluate the specificity of the method. These effects were studied because different matrices were used in the applicative part below, and the response of each analyte in each the matrix had to be known. In addition, it can allow for the determination of whether linearity can be performed under standard conditions or using a real matrix. Thus, $50 \mu \mathrm{g} / \mathrm{L}$ of each analyte was added to each matrix, extracted by DLLME and analyzed by GC-MS (five independent replicates). The reduced areas were calculated, and statistical tests were performed. As explained by Roland and Schneider, ${ }^{31}$ the matrix effect calculations are performed in three steps, $S_{\text {pooled }}^{2}, S_{\text {diff }}$ and then $\mathrm{SD}_{\text {red, }}$, according to the following formulas:

$$
\begin{aligned}
& S_{\text {pooled }}^{2}=\frac{\left(n_{1}-1\right) S_{1}^{2}+\left(n_{2}-1\right) S_{2}^{2}}{\left(n_{1}-1\right)+\left(n_{2}-1\right)} \\
& S_{\text {diff }}=S_{\text {pooled }} \sqrt{\frac{1}{n_{1}}+\frac{1}{n_{2}}}
\end{aligned}
$$


Table 2. Validation Parameters for the Developed Method Using Fermented SM as the Matrix

\begin{tabular}{|c|c|c|c|c|c|c|c|c|c|c|}
\hline \multirow[b]{2}{*}{ compound } & \multicolumn{2}{|c|}{ interday RSD (\%) } & \multirow{2}{*}{$\frac{\text { intraday RSD (\%) }}{50 \mu \mathrm{g} / \mathrm{L}}$} & \multicolumn{2}{|c|}{ linearity $^{a}$} & \multicolumn{2}{|c|}{ recovery (\%) } & \multicolumn{2}{|c|}{ limits $^{b}(\mu \mathrm{g} / \mathrm{L})$} & \multirow{2}{*}{$\frac{\text { response factor }}{50 \mu \mathrm{g} / \mathrm{L}}$} \\
\hline & $25 \mu \mathrm{g} / \mathrm{L}$ & $\overline{50 \mu \mathrm{g} / \mathrm{L}}$ & & calibration curve & $R^{2}$ & $25 \mu \mathrm{g} / \mathrm{L}$ & $\overline{50 \mu \mathrm{g} / \mathrm{L}}$ & LOD & $\overline{\text { LOQ }}$ & \\
\hline linalool & 10.4 & 6.0 & 5.1 & $4.85 x-0.009$ & 0.991 & 103.0 & 101.2 & 5.6 & 18.7 & 0.57 \\
\hline$\beta$-citral & 10.0 & 8.3 & 4.7 & $3.94 x+0.002$ & 0.997 & 102.9 & 101.1 & 9.9 & 32.9 & 0.49 \\
\hline$\alpha$-terpineol & 9.3 & 11.5 & 4.3 & $21.07 x+0.009$ & 0.994 & 97.9 & 104.3 & 9.3 & 30.8 & 2.86 \\
\hline$\alpha$-citral & 12.0 & 9.4 & 5.5 & $5.58 x-0.001$ & 0.991 & 99.7 & 100.8 & 11.3 & 37.6 & 0.68 \\
\hline geranyl acetate & 9.5 & 6.3 & 3.5 & $9.24 x-0.032$ & 0.991 & 103.7 & 100.3 & 5.7 & 19.0 & 1.03 \\
\hline citronellol & 9.5 & 6.0 & 3.3 & $5.92 x-0.002$ & 0.992 & 101.9 & 100.5 & 8.8 & 29.4 & 0.71 \\
\hline nerol & 9.5 & 6.7 & 4.6 & $7.19 x-0.025$ & 0.993 & 98.4 & 94.6 & 8.8 & 29.2 & 0.75 \\
\hline geraniol & 19.4 & 6.2 & 8.2 & $1.45 x-0.000$ & 0.994 & 98.5 & 104.0 & 5.9 & 19.7 & 0.19 \\
\hline nootkatone & 11.3 & 9.6 & 4.7 & $1.84 x-0.002$ & 0.996 & 105.3 & 102.4 & 10.5 & 35.1 & 0.21 \\
\hline
\end{tabular}

${ }^{a}$ Linearity was statistically verified using lack-of-fit tests. ${ }^{b}$ LOD and LOQ were determined when S/N was higher than 3 and 10 , respectively.

$$
\mathrm{SD}_{\mathrm{red}}=\frac{\left|\bar{M}_{\text {diff }}\right|}{S_{\text {diff }}}
$$

where $n_{1}$ and $n_{2}$ are the number of replicates, $S_{1}$ and $S_{2}$ are the standard deviations of series 1 and 2 , and $I \bar{M}_{\text {diff }}$ is the average of the response differences.

If the $\mathrm{SD}_{\text {red }}$ is less than 2, there is no matrix effect. ${ }^{31}$

Second, the $\mathrm{SD}_{\text {red }}$ values were calculated and compared to those obtained on model wine. Whether for the comparison of the $\mathrm{SD}_{\text {red }}$ between model wine and $\mathrm{SM}$ or between model wine and white wine, the values were always below 2 (between 0.74 and 1.998) (Table 1). This statistically proves the absence of a matrix effect. Therefore, under our conditions, there is no interference by the matrix on the quantitation of these analytes using this method. However, all steps of the validation procedure were performed on the different matrices. Only the results from the fermented SM are represented. The results obtained for white wine and model wine are summarized in Tables S3 and S4 of the Supporting Information.

Then, three independent calibration curves were constructed by adding known amounts of terpenes between 10 and 200 $\mu \mathrm{g} / \mathrm{L}$, which is the representative range of terpenes in wines. To check the linearity model statistically, lack-of-fit tests were performed. For each analyte, the $R^{2}$ values were higher than 0.991 and the statistical tests were positive (Table 2). For every condition, the Fisher tests performed in the lack-of-fit procedure revealed that the terpene calibrations were linear over the range of $10-200 \mu \mathrm{g} / \mathrm{L}$ for SM, model solution, and white wine. These calibration curves were used to evaluate the accuracy of the method.

The accuracy of the method was assessed by adding 25 and $50 \mu \mathrm{g} / \mathrm{L}$ of each compound to the SM (Table 2). By comparison of the added concentrations and the calculated concentrations, we evaluated the recovery of the method. The relative recovery ranges obtained for each molecule for the two amounts $(25$ and $50 \mu \mathrm{g} / \mathrm{L}$ ) were between 94.6 and $104 \%$, indicating satisfactory method accuracy.

The repeatability and intermediate reproducibility were evaluated by calculating the intra- and interday variabilities. The repeatability was performed at one concentration level (the addition of $50 \mu \mathrm{g} / \mathrm{L}, 10$ replicates of one sample on the same day), and the intermediate reproducibility was performed at two concentration levels (addition of 25 or $50 \mu \mathrm{g} / \mathrm{L}$, independent triplicates on five different days). The intraday RSD (\%) was between 3.3 and $8.2 \%$ (Table 2). For each analyte, the interday RSD (\%) was below $20 \%$, regardless of the concentration added (between 9.3 and $19.4 \%$ for $25 \mu \mathrm{g} / \mathrm{L}$ and between 6.0 and $11.5 \%$ for $50 \mu \mathrm{g} / \mathrm{L}$ ). For repeatability, the
RSD values for the intermediate reproducibility were acceptable and satisfactory in the validation procedure.

In addition, blank samples were included in the run sequence, and no signal that could interfere with the desired analytes was observed, even after the highest point of the linear range. This result bears witness to the absence of memory effects after run analysis.

The LODs and LOQs were measured. They were determined by considering $\mathrm{S} / \mathrm{N}(>3$ and $>10$, respectively). The results are shown in Table 2 . The limits were lower for linalool, geraniol, and geranyl acetate, with LODs of 5.6, 5.9, and $5.7 \mu \mathrm{g} / \mathrm{L}$, respectively. In contrast, the method seems to be less sensitive for nootkatone and $\alpha$-citral (LODs of 10.5 and 11.3, respectively). Despite these higher values, the method is sensitive enough for the studied compounds. Indeed, in wines, terpenoid concentrations can exceed $5 \mathrm{mg} / \mathrm{L}$ for some cultivars, such as Muscat. ${ }^{32}$ For other grape varieties, the concentration can greatly differ depending upon the cultivar. For instance, the content of geraniol can be $13 \mu \mathrm{g} / \mathrm{L}$ for Cinsault or $26 \mu \mathrm{g} / \mathrm{L}$ for Riesling. ${ }^{9}$ In addition, only a few studies have focused on the ability of yeasts to produce terpenoids as a result of their metabolism. ${ }^{5}$ This study highlighted that $S$. cerevisiae could intrinsically produce between 5 and $10 \mu \mathrm{g} / \mathrm{L}$ monoterpenols. This is why a sensitive and accurate method had to be developed and validated.

Diversity of Terpene Production by Wine Yeasts during Fermentation. To draw up a global picture of the contribution of yeasts to terpenol formation during winemaking, the production of terpenoids was quantitated at the end of the carried out fermentations using a collection of 40 wine yeasts and 2 natural musts (Chardonnay and Ugni Blanc) with different characteristics (sugar, nitrogen, and lipid contents). This experimental design allowed us first to assess the diversity within wine yeasts ( 28 S. cerevisiae strains and 12 non-Saccharomyces yeasts widely isolated from the wine environment) regarding their capacity to synthesize or liberate terpenoids from precursors depending upon grape juice composition. Furthermore, to assess the relative importance of de novo synthesis by yeasts versus release from varietal precursors in the terpene profile of wine, we also used a SM with characteristics similar to those of Chardonnay in terms of sugars, YAN content, $\mathrm{pH}$, and added phytosterols but without terpene precursors. Finally, a control was carried out by incubating the SM in the absence of cells for 10 days at $24^{\circ} \mathrm{C}$. Under these conditions, no terpene production was observed, indicating that no chemical reaction took place. Consequently, the terpene production discussed hereafter is only due to yeast activity (metabolism and/or enzymatic activity). 


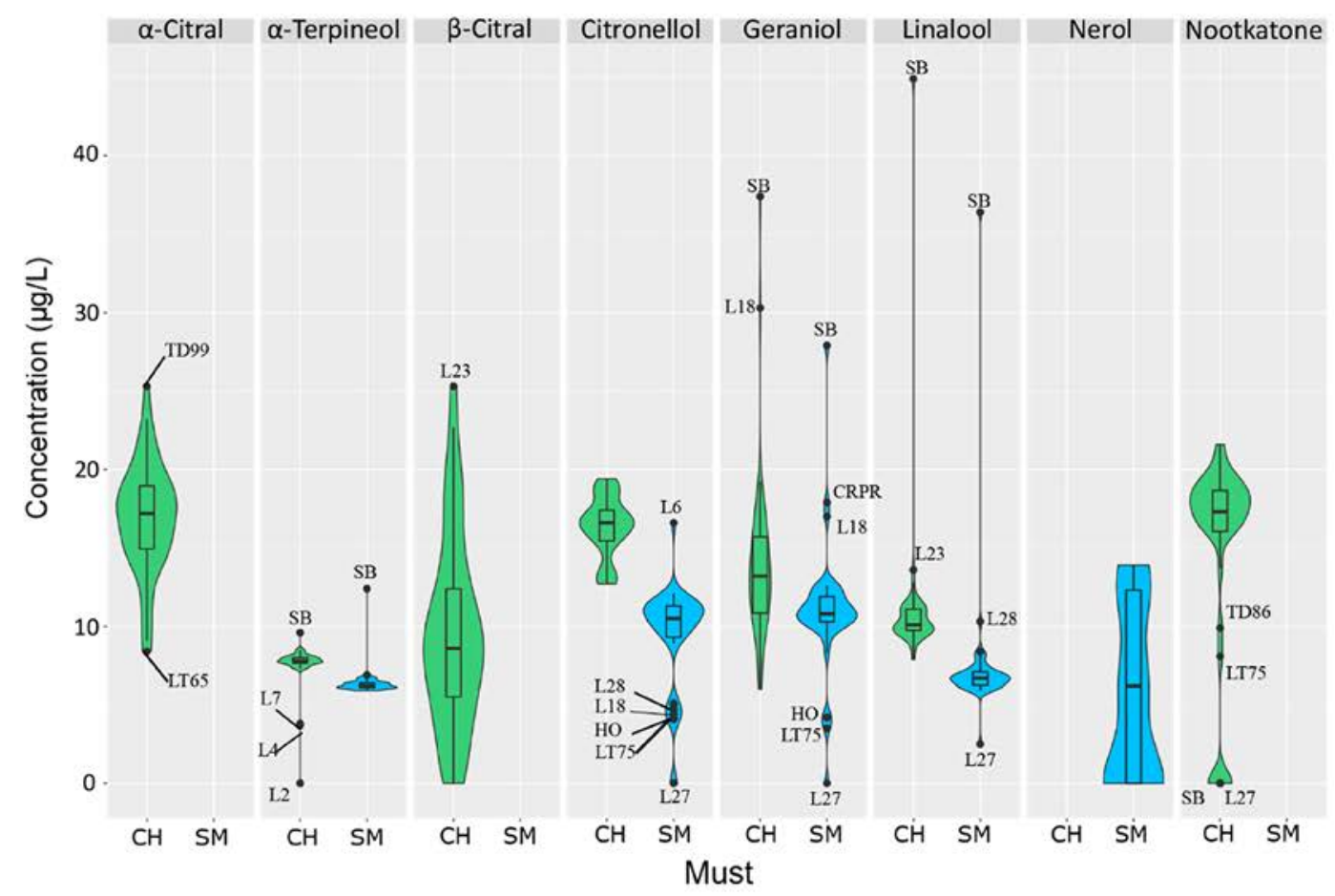

B

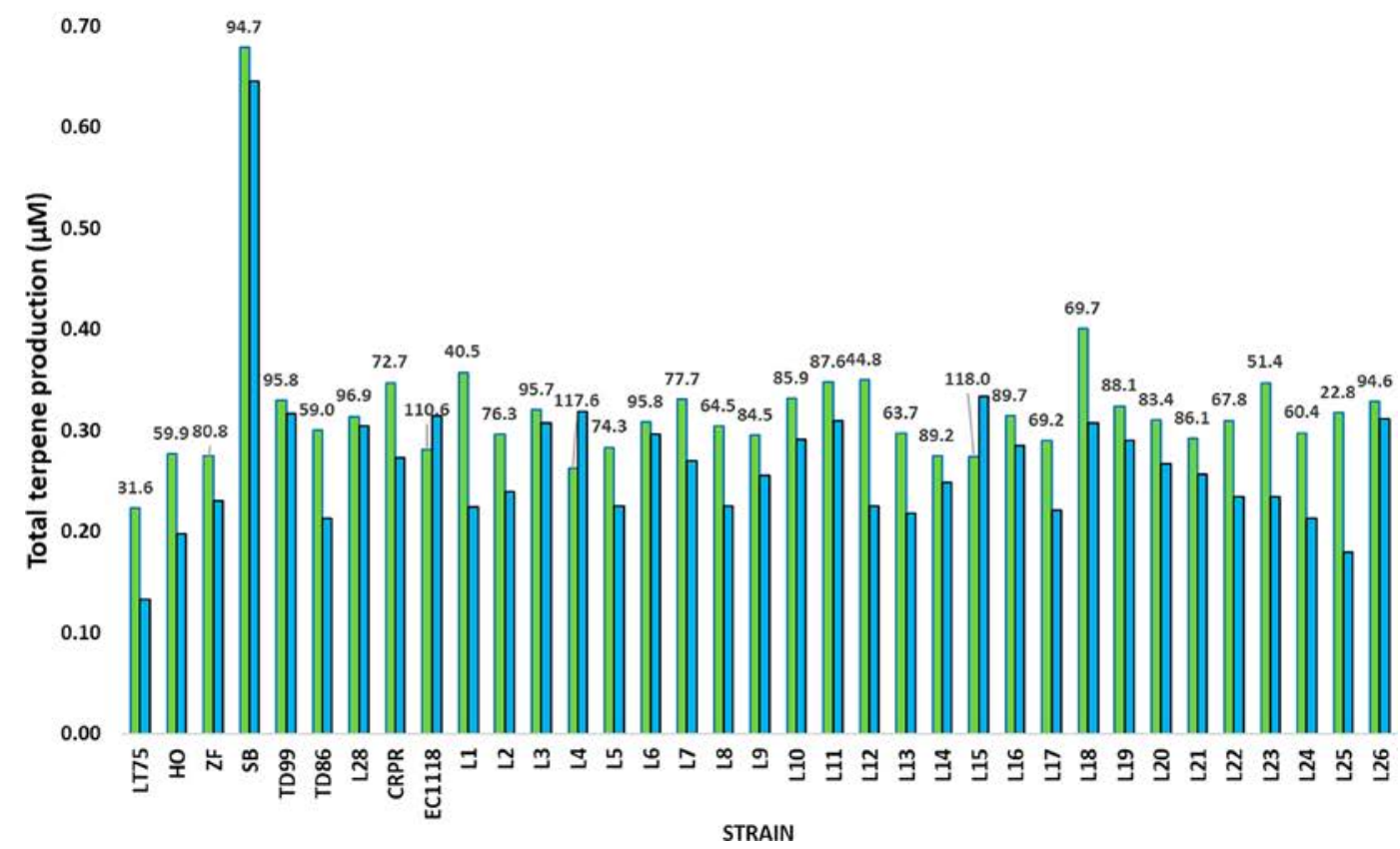

Figure 1. Production of terpenoids by 40 wine yeasts after fermentations in synthetic must (SM, blue) and $\mathrm{Chardonnay}(\mathrm{CH}$, green). Fermentations were carried out in duplicate. (A) Concentration of each produced studied terpene. (B) Sum of terpene production by yeast. Only the terpenes produced in SM are summed. The numbers on the barplots represent the percent terpenes produced by yeast metabolism.

Regardless of the culture conditions, the non-Saccharomyces strains consumed at least $60 \%$ of the initial sugars (except for L27 and L29), while all of the S. cerevisiae strains completed fermentation (Figure S1 of the Supporting Information).
To investigate the intrinsic ability of wine yeasts to produce terpene derivatives, the production profiles obtained during Chardonnay and SM fermentation were compared (Figure 1). First, during the fermentations on SM, only five of the nine 


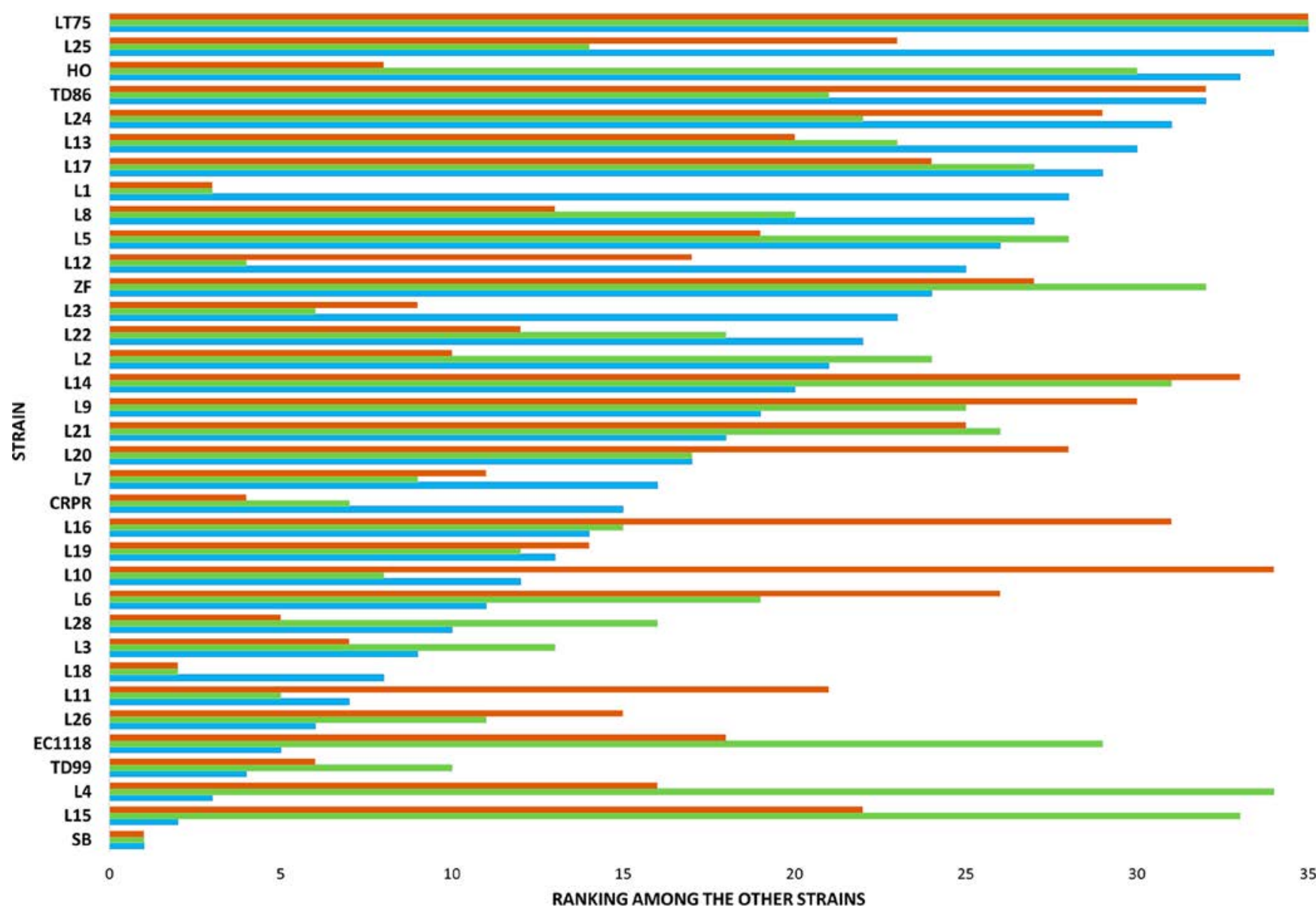

Figure 2. Terpene production ranking of each yeast after fermentation of three different musts: (green) fermentations of Chardonnay, (blue) fermentations of SM, and (red) fermentations of Ugni Blanc. The strains were first classified according to their production ranking in SM. Strains are ranked between the 1 st and 35 th most productive (five fermentations were contaminated).

terpene compounds analyzed were produced between 5 and 10 $\mu \mathrm{g} / \mathrm{L}$ on average by all of the strains, with a few exceptions: $\alpha$ terpineol, citronellol, geraniol, linalool, and nerol (Figure 1A). This observation shows the capacity of these wine yeasts to produce terpenes, without the presence of any precursor, likely through leucine catabolism or the MVA pathway. ${ }^{5}$ Conversely, $\alpha$-citral, $\beta$-citral, and nootkatone were produced only during Chardonnay fermentation, showing an exclusive production of these compounds by hydrolysis of varietal precursors or, in the case of nootkatone, by further metabolism of valencene, a sesquiterpene plant precursor provided by grapes. ${ }^{33}$ Furthermore, in the case of $\alpha$-terpineol, citronellol, geraniol, and linalool, the production in Chardonnay was only slightly higher than that measured in the SM (Figure 1A), indicating that de novo synthesis may account for a large part of the production of these molecules (up to $96.9 \%$ ) during wine fermentation.

Then, to further analyze the relative contribution of the two main origins of terpenols in wines (de novo synthesis versus release from varietal precursors), we compared the variations in total terpene production between Chardonnay and the SM for each strain (Figure 1B). Overall, the formation of terpenes was only slightly increased by the use of Chardonnay fermentation compared to SM, underlying the substantial contribution of de novo synthesis to terpene formation during wine fermentation (between 22.8 and $96.9 \%$ of total production). Nevertheless, we found that some terpenes originating from varietal precursors depended upon the strain.
A large increase in the total terpene production by L25, LT75, and L12 was observed during Chardonnay fermentation (77.2, 68.4 , and $55.2 \%$, respectively), pointing out the capacity of these strains to produce hydrolytic enzymes involved in the release of terpenes from their glycosylated precursors present in the must. In contrast, terpene production by $S$. bacillaris $(0.7$ $\mu \mathrm{M}$ total terpenes) was mainly due to yeast metabolism (94.7\%), and a decrease in the total terpene concentration was observed in Chardonnay wines produced by L15, EC1118, and L4 in comparison to synthetic wines. This last observation may be related to the absence of nerol production after Chardonnay fermentation (Figure 1A). However, our conclusions must be considered, taking into account the fact that the total terpene production measured in our experiment is low compared to the terpene content usually measured in wines (between 83 and $4040 \mu \mathrm{g} / \mathrm{L}){ }^{9}{ }^{9}$ which may reflect the oxidation of the varietal precursors in Chardonnay that must be used in this study.

The incidence of the genetic background of the yeast used during fermentation was also observed at the level of each compound. The production of geraniol varied from $6 \mu \mathrm{g} / \mathrm{L}$ (for LT75) to $37 \mu \mathrm{g} / \mathrm{L}$ (for S. bacillaris). The same observation can be made for $\alpha$-citral (between 8 and $25 \mu \mathrm{g} / \mathrm{L}$ ), $\beta$-citral (between 0 and $25 \mu \mathrm{g} / \mathrm{L}$ ), linalool (between 9 and $44 \mu \mathrm{g} / \mathrm{L}$ in Chardonnay), and nootkatone (from 0 to $21 \mu \mathrm{g} / \mathrm{L}$ ). These results show the importance of the yeast strain used for fermentation for the production of aromatic compounds. 
Furthermore, geraniol, linalool, and citronellol are produced at higher concentrations than nerol or $\alpha$-terpineol, which is in agreement with literature data. This can be explained by the fact that geraniol is the first intermediate of the monoterpenol biosynthesis pathway from GPP, which is further converted to citronellol or linalool. ${ }^{8}$ Then, linalool can be converted to $\alpha$ terpineol. The mechanisms involved in monoterpenol interconversions have not yet been fully elucidated. First, chemical conversions have been demonstrated, as after 5 days at $25{ }^{\circ} \mathrm{C}$ in a model wine, a solution initially containing $96 \%$ geraniol and $2 \%$ nerol evolved into a solution containing $72 \%$ geraniol, $22 \%$ linalool, $0.5 \% \alpha$-terpineol, and $2 \%$ nerol. $^{7}$ Furthermore, there was no modification in a solution containing only $\alpha$-terpineol, which confirms what King et al. showed, ${ }^{8}$ suggesting that this compound was the end product of the pathway. However, the contribution of yeasts to these interconversions should not be ruled out but should be demonstrated experimentally.

Finally, we compared the production of the total terpenes by each strain after fermentation of Ugni Blanc, SM, and Chardonnay to study whether the composition of must has an influence on the production of terpenes by yeasts (Figure 2 ). Regardless of the must, $S$. bacillaris was the highest producer of terpenes. However, important variations in the terpene production rank of each strain depending upon the must were observed, indicating substantial interactions between the strains and the must for terpene production. This observation is applicable to both non-Saccharomyces strains and $S$. cerevisiae strains. Thus, L15 was the 2 nd highest producer from the SM but only the 22nd from Ugni Blanc and the 33rd from Chardonnay. We can make the same observations for L4 (3rd, 16th, and 34th, respectively) or EC1118 (5th, 18th, and 29th, respectively). We can hypothesize that this observation can be linked to the higher nerol production in the SM (a different balance of nerol and geraniol leading to nerol production) but also to a poor ability of these yeasts to hydrolyze glycosylated precursors in natural musts. In contrast, S. cerevisiae strains L18 and L1 were ranked 2nd and 3rd for Chardonnay and Ugni Blanc but 8th and 27th for the SM, which was likely due to the efficiency of these strains to execute $\beta$-glucosidase activities. ${ }^{15}$ All of these elements led us to assume that there is strain variability among the $S$. cerevisiae studied species. Finally, for some strains, there is a substantial difference between the two natural musts: L6, L11, and L16 (19th, 5th, and 15th for Chardonnay, respectively, and 26th, 21st, and 31st for Ugni Blanc, respectively). This highlights the complexity of terpene production, probably as a result of its multifactorial regulation.

To conclude, in this study, an analytical method based on the use of DLLME has been developed and validated to quantitate terpenoids in wines. This method is in line with a high-throughput approach as a result of its simplicity and ease of implementation. In addition, DLLME is economically and environmentally friendly as a result of the lower volumes of organic solvents compared to commonly used extraction techniques. We applied this method to screen 40 yeast strains and confirmed that the yeasts were intrinsically able to produce terpenoids during fermentation, probably through sterol metabolism or leucine catabolism. Generally, the production was higher in the natural musts than in the SM, probably as a result of the presence of glycosylated terpene precursors. We have shown a strain effect of the production of terpenes but also an effect of the must. In addition, the S. bacillaris strains are the highest producers of geraniol, linalool, and $\alpha$-terpineol, regardless of the must. This is another example showing the potential of using non-Saccharomyces yeast species to bring new organoleptic properties and to diversify wine.

\section{ASSOCIATED CONTENT}

\section{(s) Supporting Information}

The Supporting Information is available free of charge at https://pubs.acs.org/doi/10.1021/acs.jafc.9b08222.

Retention times and qualifying and quantifying ions for the studied compounds (Table S1), composition of the natural musts used in the study (Table S2), comparison of the linearities studied on the three studied matrixes (Table S3), (A) interday and (B) intraday coefficient of variation $(\mathrm{CV}, \%)$ on the three studied matrixes (Table S4), concentrations of terpenoids produced by yeasts after fermentation on (A) Chardonnay, (B) Ugni Blanc, and (C) SM (Table S5), and fermentation progress of the studied wine yeasts in the three different musts (Figure S1) (PDF)

\section{AUTHOR INFORMATION}

\section{Corresponding Author}

G. Bergler - Martell Mumm Perrier-Joüet, Pernod Ricard, 16000 Cognac, France; SPO, University Montpellier, INRAE, Montpellier SupAgro, 34060 Montpellier, France; 이이. org/ 0000-0002-5540-0269; Phone: +33650298882;

Email: guillaume.bergler@supagro.fr

\section{Authors}

V. Nolleau - SPO, University Montpellier, INRAE, Montpellier SupAgro, 34060 Montpellier, France

C. Picou - SPO, University Montpellier, INRAE, Montpellier SupAgro, 34060 Montpellier, France

M. Perez - SPO, University Montpellier, INRAE, Montpellier SupAgro, 34060 Montpellier, France

A. Ortiz-Julien - Lallemand SAS, 31702 Blagnac, France

M. Brulfert - Martell Mumm Perrier-Joüet, Pernod Ricard, 16000 Cognac, France

C. Camarasa - SPO, University Montpellier, INRAE,

Montpellier SupAgro, 34060 Montpellier, France

A. Bloem - SPO, University Montpellier, INRAE, Montpellier SupAgro, 34060 Montpellier, France

\section{Notes}

The authors declare no competing financial interest.

\section{ACKNOWLEDGMENTS}

The authors thank Dr. Aurélie Roland for help concerning the validation of the method and her useful advice and discussions.

\section{REFERENCES}

(1) Pretorius, I. S.; Høj, P. B. Grape and Wine Biotechnology: Challenges, Opportunities and Potential Benefits. Aust. J. Grape Wine Res. 2005, 11 (2), 83-108.

(2) Swiegers, J. H.; Bartowsky, E. J.; Henschke, P. A.; Pretorius, I. S. Yeast and Bacterial Modulation of Wine Aroma and Flavour. Aust. J. Grape Wine Res. 2005, 11 (2), 139-173.

(3) Pérez-Gil, J.; Rodríguez-Concepción, M.; Vickers, C. E. Formation of Isoprenoids. In Biogenesis of Fatty Acids, Lipids and 
Membranes; Geiger, O., Ed.; Springer International Publishing: Cham, Switzerland, 2017; pp 1-29, DOI: 10.1007/978-3-319-43676-0_6-1.

(4) TouzÉ, T.; Mengin-Lecreulx, D. Undecaprenyl Phosphate Synthesis. EcoSal Plus 2008, DOI: 10.1128/ecosalplus.4.7.1.7.

(5) Carrau, F. M.; Medina, K.; Boido, E.; Farina, L.; Gaggero, C.; Dellacassa, E.; Versini, G.; Henschke, P. A. Novo Synthesis of Monoterpenes by Saccharomyces cerevisiae Wine Yeasts. FEMS Microbiol. Lett. 2005, 243 (1), 107-115.

(6) Park, S. K.; Noble, A. C. Monoterpenes and Monoterpene Glycosides in Wine Aromas. In Beer and Wine Production; Gump, B. H., Pruett, D. J., Eds.; American Chemical Society (ACS): Washington, D.C., 1993; Vol. 536, Chapter 6, pp 98-109, DOI: 10.1021/bk-1993-0536.ch006.

(7) Pedersen, D. S.; Capone, D. L.; Skouroumounis, G. K.; Pollnitz, A. P.; Sefton, M. A. Quantitative Analysis of Geraniol, Nerol, Linalool, and $\alpha$-Terpineol in Wine. Anal. Bioanal. Chem. 2003, 375 (4), 517522 .

(8) King, A.; Richard Dickinson, J. Biotransformation of Monoterpene Alcohols by Saccharomyces cerevisiae, Torulaspora delbrueckii and Kluyveromyces lactis. Yeast 2000, 16 (6), 499-506.

(9) Gunata, Y. Z.; Bayonove, C. L.; Baumes, R. L.; Cordonnier, R. E. The Aroma of Grapes I. Extraction and Determination of Free and Glycosidically Bound Fractions of Some Grape Aroma Components. J. Chromatogr. A 1985, 331, 83-90.

(10) Marais, J. Terpenes in the Aroma of Grapes and Wines: A Review. South Afr. J. Enol. Vitic. 2017, 4 (2), 49-58.

(11) Lambrechts, M. G.; Pretorius, I. S. Yeast and Its Importance to Wine Aroma-A Review. South Afr. J. Enol. Vitic. 2000, 21 (1), 97129.

(12) Vasserot, Y.; Arnaud, A.; Galzy, P. Monoterpenol glycosides in plants and their biotechnological transformation. Acta Biotechnol. 1995, 15 (1), 77-95.

(13) Gunata, Z.; Bitteur, S.; Brillouet, J.-M.; Bayonove, C.; Cordonnier, R. Sequential Enzymic Hydrolysis of Potentially Aromatic Glycosides from Grape. Carbohydr. Res. 1988, 184, 139149.

(14) Maicas, S.; Mateo, J. J. Hydrolysis of Terpenyl Glycosides in Grape Juice and Other Fruit Juices: A Review. Appl. Microbiol. Biotechnol. 2005, 67 (3), 322-335.

(15) Hernandez, L. $\beta$-Glucosidase Activity in a Saccharomyces cerevisiae Wine Strain. Int. J. Food Microbiol. 2003, 80 (2), 171-176.

(16) Swangkeaw, J.; Vichitphan, S.; Butzke, C. E.; Vichitphan, K. Characterization of $\beta$-Glucosidases from Hanseniaspora sp. and Pichia anomala with Potentially Aroma-Enhancing Capabilities in Juice and Wine. World J. Microbiol. Biotechnol. 2011, 27 (2), 423-430.

(17) Lynen, F. Biosynthetic Pathways from Acetate to Natural Products. Pure Appl. Chem. 1967, 14 (1), 137-167.

(18) Zgoła-Grześkowiak, A.; Grześkowiak, T. Dispersive LiquidLiquid Microextraction. TrAC, Trends Anal. Chem. 2011, 30 (9), 1382-1399.

(19) Arthur, C. L.; Pawliszyn, J. Solid Phase Microextraction with Thermal Desorption Using Fused Silica Optical Fibers. Anal. Chem. 1990, 62 (19), 2145-2148.

(20) Zhao, X.; Fu, L.; Hu, J.; Li, J.; Wang, H.; Huang, C.; Wang, X. Analysis of PAHs in Water and Fruit Juice Samples by DLLME Combined with LC-Fluorescence Detection. Chromatographia 2009, 69 (11-12), 1385-1389.

(21) Prosen, H.; Zupančič-Kralj, L. Solid-Phase Microextraction. TrAC, Trends Anal. Chem. 1999, 18 (4), 272-282.

(22) Berijani, S.; Assadi, Y.; Anbia, M.; Milani Hosseini, M.-R.; Aghaee, E. Dispersive Liquid-Liquid Microextraction Combined with Gas Chromatography-Flame Photometric Detection. J. Chromatogr. A 2006, 1123 (1), 1-9.

(23) Rezaee, M.; Assadi, Y.; Milani Hosseini, M.-R.; Aghaee, E.; Ahmadi, F.; Berijani, S. Determination of Organic Compounds in Water Using Dispersive Liquid-Liquid Microextraction. J. Chromatogr. A 2006, 1116 (1-2), 1-9.

(24) Al-Saidi, H. M.; Emara, A. A. A. The Recent Developments in Dispersive Liquid-Liquid Microextraction for Preconcentration and
Determination of Inorganic Analytes. J. Saudi Chem. Soc. 2014, 18 (6), 745-761.

(25) Farhadi, K.; Farajzadeh, M. A.; Matin, A. A. Liquid Chromatographic Determination of Benomyl in Water Samples after Dispersive Liquid-Liquid Microextraction. J. Sep. Sci. 2009, 32 (14), 2442-2447.

(26) Nagaraju, D.; Huang, S.-D. Determination of Triazine Herbicides in Aqueous Samples by Dispersive Liquid-Liquid Microextraction with Gas Chromatography-Ion Trap Mass Spectrometry. J. Chromatogr. A 2007, 1161 (1-2), 89-97.

(27) Fariña, L.; Boido, E.; Carrau, F.; Dellacassa, E. Determination of Volatile Phenols in Red Wines by Dispersive Liquid-Liquid Microextraction and Gas Chromatography-Mass Spectrometry Detection. J. Chromatogr. A 2007, 1157 (1-2), 46-50.

(28) Rollero, S.; Bloem, A.; Camarasa, C.; Sanchez, I.; Ortiz-Julien, A.; Sablayrolles, J.-M.; Dequin, S.; Mouret, J.-R. Combined Effects of Nutrients and Temperature on the Production of Fermentative Aromas by Saccharomyces cerevisiae during Wine Fermentation. Appl. Microbiol. Biotechnol. 2015, 99 (5), 2291-2304.

(29) Leong, M.-I.; Huang, S.-D. Dispersive Liquid-Liquid Microextraction Method Based on Solidification of Floating Organic Drop for Extraction of Organochlorine Pesticides in Water Samples. J. Chromatogr. A 2009, 1216 (45), 7645-7650.

(30) Mao, T.; Hao, B.; He, J.; Li, W.; Li, S.; Yu, Z. Ultrasound Assisted Ionic Liquid Dispersive Liquid Phase Extraction of Lovastatin and Simvastatin: A New Pretreatment Procedure. J. Sep. Sci. 2009, 32 (17), 3029-3033.

(31) Roland, A.; Schneider, R. Development and Validation of a High-Throughput Analysis of Glutathione in Grapes, Musts and Wines by Stable Isotope Dilution Assay and LC-MS/MS. Food Chem. 2015, 177, 152-157.

(32) Rapp, A.; Mandery, H.; Ullmeyer, H. Neue Monoterpendiole in Traubenmosten Und Weinen Und Ihre Bedeutung Für Die Genese Cyclischer Monoterpenäther. Vitis 1984, 23, 84-92.

(33) Fraatz, M. A.; Berger, R. G.; Zorn, H. Nootkatone-A Biotechnological Challenge. Appl. Microbiol. Biotechnol. 2009, 83 (1), 35-41.

(34) Babushok, V. I.; Linstrom, P. J.; Zenkevich, I. G. Retention Indices for Frequently Reported Compounds of Plant Essential Oils. J. Phys. Chem. Ref. Data 2011, 40 (4), No. 043101. 